\title{
Construção da identidade organizacional na indústria criativa: o caso de uma emissora de rádio*
}

\author{
Edson Keyso de Miranda Kubo ${ }^{l}$ \\ Universidade Municipal de São Caetano do Sul
}

Embora a indústria criativa continue a se expandir há ainda poucas pesquisas sobre este setor e sua identidade organizacional no Brasil (BENDASSOLI et al., 2007). Com o objetivo de refletir sobre a construção da identidade organizacional nesta indústria, esta pesquisa escolheu uma de suas organizações representantes que é a emissora de rádio $\mathrm{X}$. Utilizou-se para isso de métodos qualitativos, levantamento de dados sobre sua história e análise de conteúdo de entrevistas não-estruturadas com especialistas sobre esta organização. O processo de construção de identidade da emissora de rádio $\mathrm{X}$ partiu do rompimento com os típicos paradigmas deste setor no Brasil para que fosse possível maior isenção, utilidade das informações, prestatividade e proximidade com o publico. Concluiuse que a emissora de rádio $\mathrm{X}$ se utiliza de imagens emanadas do "âncora" e principalmente do "gerenciamento da impressão" para construção de sua identidade organizacional.

Palavras-chave: Indústria criativa Emissora de rádio - Identidade organizacional - Gerenciamento da impressão.
Although creative industry keeps growing there are still a few researches about creative industry and its organizational identity in Brazil (BENDASSOLI et al., 2007). In order to ponder on the construction of the organizational identity in this industry, this research chose one of its representative organizations, radio broadcaster $\mathrm{X}$ (fictive name). It utilized a qualitative approach through data analysis about its history and content analysis of semi-structured interviews with specialists in this organization. The process about the construction of identity of the radio broadcaster $\mathrm{X}$ began from the rupture with the typical paradigms of this sector in Brazil so that it was possible to provide more transparency, information utility, readiness and proximity with the public. It concludes that radio broadcaster X utilizes images emanated from the "anchor" and mainly the impression management to construct its organizational identity.

Keywords: Creative industry - Radio broadcaster - Organizational identity - Impression management.

\footnotetext{
* Construction of organizational identity in creative industry: the case of a radio broadcaster.

${ }^{1}$ Doutor em Administração (EAESP-FGV), Professor do Programa de Pós-Graduação em Administração (PPGA), Universidade Municipal de São Caetano do Sul. Endereço para correspondências: Av. Celso Garcia, 1907, Bloco 25, Apto. 71, Belenzinho, São Paulo, SP, 03015-000 (edsonkubo@gvmail.br)
} 


\title{
HUMANAS
}

\section{Introdução}

\begin{abstract}
$\mathrm{A}$ s organizações criativas encaram o conhecimento como o principal fator de produção (DEAN \& KRETSCHMER, 2007) e sob essa contexto, configuram-se organizações que se utilizam de recursos flexíveis e intangíveis como, por exemplo, da criatividade e capacidade de inovação, a fim de se adaptar às demandas do ambiente. A abordagem da pluralidade e análise crítica dos acontecimentos é uma necessidade imposta pela era pós-industrial (HUBER, 1984). A emissora de rádio é uma organização da indústria criativa que incorpora essas novas tendências, utilizando-se de criatividade e de ideias na hora de prestar serviços.
\end{abstract}

Essa organização criativa precisa interpretar fatos na hora em que ocorrem, criar sinergias com artefatos culturais diversos, tais como textos, impressos, áudio. Além disso, destaca-se a relevância dessa atividade no aspecto econômico, pois tem crescido consideravelmente nos EUA, na Inglaterra, no Brasil e no Mundo (BENDASSOLI et al., 2007). Como organização do ramo criativo, emissora de rádio precisa lidar com os desafios inerentes à heterogeneidade dos gostos da audiência e com o desafio de manter a qualidade através de um produto final intangível, típico da área de serviços.

Em organizações criativas, como a emissora de rádio, a identidade organizacional parece depender em maior grau do tipo de imagem que os ouvintes possuem a seu respeito, pois o seu produto final (serviços) é intangível e necessita de impressões favoráveis por parte dos ouvintes. De acordo com Goya e colaboradores (2000), a identidade organizacional consiste no entendimento coletivo das características consideradas centrais e relativamente permanentes de uma organização, que a tornam diferente das demais organizações. Já a imagem é o modo pelo qual a organização é enxergada pelos outros, ou seja, a percepção pública ou impressão sobre a organização, geralmente associada a uma determinada ação ou evento. O ponto principal entre os dois conceitos é o modo como a imagem consegue desestabilizar ou estimular mudanças na identidade organizacional (SCHULTZ \& CORLEY, 2000).

Quando se abordam as emissoras de rádio no Brasil, é importante notar que certos paradigmas permaneceram durante muito tempo para este setor: uma bela voz é a principal ferramenta do radiojornalismo; o radiojornalismo não tem audiência e não se sustenta economicamente e o desafio da isenção devido aos interesses da oligarquia política (TAVARES \& GIOVANI, 2006). Assim, a superação desses paradigmas implica em uma mudança da identidade organizacional por parte deste tipo de organização criativa.

O objetivo deste artigo é entender em princípio como a emissora de rádio lidou com esses paradigmas que durante muito tempo predominaram sobre esse tipo de ramo da indústria criativa no Brasil. Não obstante, 
devido à escassa literatura sobre o tema, o autor escolheu o caso emissora da radio $\mathrm{X}$ (nome ficíticio), pela construção de uma identidade organizacional peculiar, que aparentemente inovou frente às demais. Portanto, a pergunta de pesquisa que norteará este artigo é: Como se configurou a formação de identidade da emissora da radio X?

Este artigo está dividido da seguinte maneira: uma visão geral da produção acadêmica sobre a atividade de uma emissora de rádio e o seu referencial principal; os procedimentos metodológicos de pesquisa qualitativa adotados para este artigo, a apresentação dos resultados e as considerações finais.

\section{A emissora de rádio no contexto da indústria criativa}

O termo indústrias criativas surgiu nos anos 1990, primeiramente em estudos provenientes da Inglaterra e Austrália. Atualmente contempla os setores e organizações nas quais a criatividade seja uma dimensão essencial, tais como publicidade, cinema, teatro, artesanato, arquitetura, design, música, indústria editorial, emissora de rádio, TV e desenvolvimento de software.

Assim, a partir do momento em que as nações industrializadas começaram a enfatizar não apenas a produção de bens e serviços, mas também a produção de ideias e conhecimento, as indústrias criativas tornaram-se objeto de uma crescente quantidade de pesquisas, aumentando dessa forma o conteúdo teórico existente sobre o tema. São exemplos pioneiros desses estudos os trabalhos promovidos por Landry e Bianchini (1995), Csikszentmihalyi (1996), O'Connor e Wynne (1996) e Robinson (2001).

Uma definição muito difundida para o termo "indústrias criativas" foi exposta pelo Departamento de Cultura, Mídia e Esportes do governo britânico em 1998 e resgatada por Jones et al. (2004): indústrias criativas são organizações que têm origem na criatividade, habilidade e talento individuais, tendo ainda potencial para geração de prosperidade e criação de empregos através da exploração de propriedade intelectual. Entretanto, Tepper (2002) argumenta que é muito difícil encontrar um consenso sobre os limites conceituais da indústria criativa. Porém, um ponto comum que todas as organizações que acreditem se encaixar nessa descrição devem ter é a idéia do esforço criativo oriundo do conhecimento gerado pela própria organização, como premissa básica de sua razão de existir. Corroborando tal idéia, Cook (1998) acredita que o conhecimento e a criatividade sejam importantes fontes de competitividade para as organizações pertencentes às indústrias criativas. Assim, esse artigo propõe a análise de uma das organizações dessa indústria que é a emissora de rádio.

As pesquisas envolvendo emissoras de rádio abordam em geral aspectos peculiares de medição de audiência, prestação de serviços e publicidade. 


\section{HUMANAS}

A audiência de uma emissora constitui uma das mais desafiadoras mass media, que abrangem todas as organizações que fornecem informações para o público tais como televisão e jornais, a ser mensurada. A pesquisa de audiência na emissora de rádio é falha pois se baseia no Recall, na qual a medição de audiência é feita por intermédio de entrevistas domiciliares, na qual o pesquisador pergunta ao entrevistado se ele ouviu determinada emissora e, em caso positivo, que programas, baseando-se na memória da pessoa. Há várias produções acadêmicas envolvendo a busca por melhores metodologias de medição (TAVERES \& GIOVANI, 2006). Isso acontece pelo fato da emissora de rádio estar disponível virtualmente em qualquer local e qualquer horário, podendo representar uma atividade individual ou grupal.

A intensidade da audiência abrange uma amplitude vasta de ouvintes: desde a audiência passiva até ouvintes que deliberadamente escolhem o canal da emissora de rádio que mais se adequa as suas preferências. Devido isso, a emissora de rádio é identificada como a mass media mais pessoal e confiável no que tange ao relacionamento com seus usuários (ROBINSON, 2000). Devese ressaltar, porém, que grande parte da audiência de uma emissora de rádio se enquadra em uma capacidade secundária de acompanhamento durante o trabalho, no automóvel, durante as refeições e, hoje, também na internet.

A atividade de uma emissora de rádio também começa a vislumbrar uma situação futura de diversidade devido à multiplicação das estações análogas à rádio interativa, à audiência via internet e ao início da rádio digital. Não obstante, o mercado de emissoras sempre esteve associado à música e ao entretenimento (TAVARES \& GIOVANI, 2006).

A importância da atividade de uma emissora de rádio se manifesta, em sua natureza, pelo improviso, rapidez e agilidade na reportagem de acontecimentos que impactam diretamente na sociedade. Além do mero entretenimento, a emissora de rádio passou a assumir papel crucial nos movimentos sociais e na formação de opinião. Nos Estados Unidos, por exemplo, em meados da década de 1990, foi fundada a Worker Independent News (WIN), que produzia um programa de rádio voltado à divulgação de notícias de lutas operárias em escala nacional. O objetivo do rádio operária WIN foi, desde o início, o estímulo à educação e ao diálogo aberto com os cidadãos, trabalhadores (JAMIESON, 2006). Conforme ressaltam Tavares e Giovani (2006), a emissora de rádio passa a ideia de um veículo companheiro interativo, on line, móvel, além ser considerada auto geradora de conteúdo, pelas múltiplas perspectivas de comentários e abordagens que proporciona acerca de um fenômeno.

Nas pesquisas envolvendo a emissora de rádio, reconhece-se, portanto, a relevância deste ramo, através da multiplicação do número de estações que surgem da atividade comercial, de frequências e de novas licenças que cobrem uma grande amplitude geográfica, populações e grupos culturais (ROBINSON, 2000). 
No caso do Brasil, a primeira emissora de rádio chegou oficialmente em 1922. Este veículo de comunicação nasce com uma programação que transmitia ópera, música clássica e palestras. Com o surgimento da TV no final dos anos 1950, houve a previsão de que seria o fim das emissoras de rádio. Porém, a invenção do transístor possibilitou o acesso aos "radinhos de pilha". Nos anos 1960, houve a inovação tecnológica que permitiu a transmissão via frequência modulada: as FM. O som ganhou então uma qualidade e pureza jamais vistas, iniciando a segmentação em rádios AM e FM. No final da década de 1970, a FM ganhou espaço com apoio dos militares, devido ao fato de possuir baixa potência e restrito alcance geográfico (TAVARES \& GIOVANI, 2006).

Conforme esses autores, essas características da rádio FM permitiam o fácil controle pelos militares e o direcionamento para a política de segurança nacional. A expansão da FM não parou, subindo de 68\% em 1993 até 77\% em 2001. Os investimentos passaram a migrar então para as FM: 70\% dos investimentos em 2001. Porém, a FM não acabou com a AM. Em relação ao impacto econômico desta atividade, enfatiza-se que a verba destinada às emissoras de rádio saltou de 3,7\% do bolo publicitário em 1997 para 4,5\% do bolo publicitário em 2006. Nos EUA e na Europa, já é realidade a rádio digital que ainda está em fase de testes no Brasil.

Quando se abordam as emissoras de rádio no Brasil, é importante notar que certos paradigmas permaneceram durante muito tempo como desafios para este setor: uma bela voz é a principal ferramenta do radiojornalismo; o radiojornalismo não tem audiência e não se sustenta economicamente; é impossível ter isenção devido aos interesses da oligarquia política (TAVARES \& GIOVANI, 2006). Para superar esses paradigmas, as emissoras de rádio deveriam se separar de uma identidade organizacional repleta de estereótipos e vícios, para assumir uma nova identidade decorrente deste distanciamento. Durante o processo de construção dessa identidade, a exclusão de uma determinada categoria inapropriada (por exemplo, emissora de rádio enquanto ferramenta de dominação da oligarquia) levaria à identidade primária que define a organização (ELSBACH \& BHATTACHARYA, 2001).

Além do esforço de construção de identidade por parte da emissora de rádio, tornava-se necessária a utilização de outros recursos, ainda pouco esclarecidos pela literatura sobre este ramo, para construir a sua identidade organizacional. Embora na emissora de rádio, a associação da comunicação com a imagem seja apregoada como pauta do futuro (TAVARES \& GIOVANI, 2006), o conceito de identidade organizacional nesse ramo da comunicação aparentemente jamais seria possível sem a utilização de imagens (ALVESSON, 1990).

O referencial teórico sugere que uma emissora de rádio aparentemente precisa se utilizar de imagens para mudar a sua identidade organizacional. 


\section{UMANAsta de Ciéncias}

Para entender esse processo, faz-se necessário o estudo de uma organização que tenha construido a sua identidade organizacional partindo dos paradigmas mencionados acima. A próxima seção descreve a emissora de rádio escolhida e os procedimento metodológicos adotados.

\section{Metodologia}

Para compreender o processo de construção de identidade e a relação entre identidade organizacional e imagem na emissora de rádio, buscou-se o exemplo de uma organização que enfrentou todos os paradigmas enunciados no tópico anterior. A organização escolhida como alvo deste artigo foi a emissora de rádio X. Essa emissora, focada em notícias, apresenta um slogan referente a um tipo de radiojornalismo (all news) até então desconhecido no Brasil.

A emissora de rádio X entrou no ar na década de 1990 e hoje tem uma rede composta por mais de 20 afiliadas em capitais e grandes cidades do país. A sua entrada representou um confronto em relação ao antigo modelo de emissora de rádio baseada exclusivamente em música e entretenimento. $\mathrm{O}$ público-alvo da emissora de rádio $\mathrm{X}$ é composto por pessoas que atuam no nível gerencial, integram as classes A e B e têm cerca de 30 anos (TAVARES \& GIOVANI, 2006). De acordo com Tavares e Giovani (2006), em seus estudos sobre o radiojornalismo no Brasil, um dos mitos comuns na década de 1990 era a ideia de que uma bela voz é uma ferramenta imprescindível para este ramo da indústria criativa. A emissora de rádio $\mathrm{X}$ ajudou a derrubar esse mito e buscou a construção de uma identidade organizacional que lhe garantiu o reconhecimento público.

Além da pesquisa bibliográfica e dos conceitos envolvendo a atividade da emissora de rádio, esta pesquisa também contemplou a análise de conteúdo de uma entrevista concedida por um especialista na história desta emissora e de uma entrevista com um dos funcionários do corpo técnico de redação da emissora de rádio $\mathrm{X}$, indicado pelo especialista. O objetivo das duas entrevistas foi confrontar as visões a respeito dos recursos que a emissora de rádio $\mathrm{X}$ utilizou para construir a sua identidade organizacional. As entrevistas com especialistas na emissora $\mathrm{X}$ foram realizadas através de um roteiro que permitia um diálogo espontâneo com os entrevistados via questionário não estruturado e aberto (COOPER \& SCHINDLER, 2003). Algumas perguntas realizadas foram: Como a emissora de rádio $\mathrm{X}$ faz para se diferenciar da concorrência? De que modo a emissora se apresenta ou quer ser vista pelos ouvintes? Que barreiras a emissora de rádio X precisou vencer para se consolidar neste segmento? 


\section{Imagem e identidade organizacional da emissora de rádio $X$}

Esta seção contempla a apresentação da análise de conteúdo das entrevistas a respeito do modo como a emissora de rádio $\mathrm{X}$ constrói ou mesmo fortalece diariamente sua imagem. Vale ressaltar que o acesso aos entrevistados foi restrito. Primeiramente o autor conseguiu acesso a um especialista na história desta emissora que atua como coordenador de um curso de comunicação em uma renomada instituição de ensino em São Paulo na área de rádio e jornalismo. Após a indicação deste especialista, foi possível o acesso a um dos integrantes da emissora de rádio $\mathrm{X}$ que concedeu a entrevista sob condição de sigilo absoluto sobre a sua identidade.

Os segmentos de dados a seguir abordam o modo utilizado pela emissora de rádio $\mathrm{X}$ para cativar os ouvintes, o diferencial, recursos e critérios para vender seus serviços. Assim, as citações mais significativas serão dispostas e comentadas e ao final da seção formarão as categorias de análise do conteúdo (BARDIN, 1977). Para compensar a ausência de imagens quando comparada à televisão, a emissora de rádio $\mathrm{X}$ se vale da descrição acurada do ambiente para levar o ouvinte a imaginar o relato de uma situação:

Na rádio, o recurso mais utizado é a descrição do ambiente para levar o ouvinte à imaginação da situação... e passar uma imagem de que rádio não é bicho-de- sete-cabeças e aí consegue trabalhar com a imagem. A rádio é mais rápida que a internet $\mathrm{e}$ precisa ser solta (Entrevistado 1).

Além disso, o paradigma de que o radiojornalismo se assenta numa bela voz parece ultrapassado por outros atributos tais como credibilidade e empatia que conferem ao âncora maior audiência:

Hoje, o interlocutor não precisa mais de uma voz bonita (Entrevistado 1).

[...] O português coloquial estreita uma relação. A rádio também cria imagem, mas hoje tem a rádio via internet onde é possível ver e ouvir o profissional da rádio. Rádio é costume. Você costuma ouvir determinado profissional e vai com ele até enjoar... Assim decidimos criar uma rádio de notícias e quebrar paradigmas (Entrevistado 2). 


\section{HUMANAS}

A credibilidade do âncora aparentemente permite à emissora de rádio $\mathrm{X}$ vender os seus serviços e obter a legitimidade frente aos seus clientes, que aceitam a associação de seus produtos com a imagem do âncora, conforme mostram as citações abaixo:

Hoje, o que conta é a credibilidade do profissional e não a voz. O que importa é a credibilidade do âncora. A credibilidade do âncora vende. O Banco $\mathrm{X}$, por exemplo, quer ter a sua publicidade associada à imagem do âncora nos anúncios de uma emissora de rádio (Entrevistado 1).

A imagem da emissora é a credibilidade. A palavra é fundamental. É óbvio que a figura do âncora é importante. O âncora personifica a credibilidade. A imagem de uma boa empresa de comunicação é criada através da credibilidade... (Entrevistado 2).

A credibilidade de uma emissora de rádio somente pode ser construída e preservada se o público perceber, ao longo do tempo, que a empresa age com imparcialidade diante dos acontecimentos. Essa foi a opinião de um dos entrevistados ao ser questionado sobre o envolvimento do âncora com organizações que patrocinam o programa e por isso pressionam para que sejam prestigiadas:

O departamento comercial é distinto da emissora. Se a TAM patrocina a emissora de rádio não significa que emissora de rádio X não vai criticar a TAM nessa crise aérea em que vivemos... (Entrevistado 2).

Os entrevistados sugerem que o conhecimento das necessidades do cliente e o tempo dispendido com as notícias sejam os critérios principais, que são utilizados pela emissora de rádio $\mathrm{X}$ em suas atividades diárias:

Emissora de rádio vive do áudio... uma reportagem malfeita e desinteressante é sentida de imediato pelo ouvinte. Hoje, você tem muita coisa para fazer, não tem? Você não pode perder tempo com notícias que não ajudam (Entrevistado 2).

Não é uma rádio popularesca. Qual é o lema? O que é que a notícia $\mathrm{X}$ vai mudar na vida do professor, do aluno, do médico, do advogado, do administrador de empresas, enfim. A partir daí você determina critérios (Entrevistado 2). 


\title{
Construção da identidade organizacional na indústria criativa: o caso de uma emissora de rádio
}

Nesse sentido, os entrevistados enfatizam a crescente importância da informação rápida, direcionada e útil, como recurso valioso e atrativo para o sucesso da emissora de rádio $\mathrm{X}$ e dos compradores dos seus serviços. Assim, a emissora $\mathrm{X}$ se diferencia de suas potenciais concorrentes que apresentam em geral recursos prontos e genéricos tais como a execução de músicas e entretenimento. O objetivo desta emissora de acordo com os entrevistados é prover os ouvintes com informações que sirvam realmente como ferramenta de tomada de decisão no cotidiano.

Na opinião do entrevistado 2 , a qualidade da transmissão da rádio digital será um diferencial para o setor, mas não substituirá a importância do âncora:

\begin{abstract}
Além disso a rádio digital vai chegar com tudo e a qualidade de transmissão vai permitir maior abrangência e sincronismo das informações em todas as regiões. Mas o papel do âncora continua sendo fundamental... (Entrevistado 2).
\end{abstract}

Vale ressaltar que a emissora de rádio $\mathrm{X}$ está inserida na realidade do mercado competitivo, em disputa pelo "bolo publicitário" e se defronta constantemente com o desafio da qualidade:

O maior desafio da X é manter a qualidade... Hoje existe uma precarização das profissões em todos os sentidos... Hoje o jornalista exerce diversas funções e manter a qualidade e o foco do que queremos é difícil (Entrevistado 2).

Portanto, observou-se que a emissora de rádio X depende da figura do "âncora" para atrair o ouvinte e aumentar a participação da emissora no bolo publicitário. De acordo com os entrevistados, o âncora é simultaneamente o repórter, o apresentador, o editor, que participa do processo de busca, checagem e disseminação de notícias e não um mero artista com uma bela voz como ditavam os paradigmas das emissoras de rádio brasileiras. O grande desafio para essa emissora de rádio foi vencer o mito de que uma identidade focada somente em radiojornalismo não cativa o público e não pode ser rentável como as emissoras com programas de música e entretenimento. Sob esse contexto, a identidade organizacional dessa emissora deveria romper com os paradigmas vigentes na maioria das emissoras brasileiras e se basear na prestação de serviço ao público com notícias de âmbito nacional que estivessem relacionadas à vida das pessoas nas cidades e que pudessem servir de apoio à tomada de decisões diárias. A seguir serão discutidos os resultados que permitem elucidar a identidade organizacional assumida pela emissora de rádio X. 


\section{HUMANAS}

\section{Discussão}

A emissora de rádio $\mathrm{X}$ apresenta o âncora como principal fator de credibilidade para os ouvintes e patrocinadores. O âncora é a imagem que a organização projeta a todo momento para atrair o ouvinte e cativá-lo. A bela voz não parece mais ser o atributo principal desta organização criativa, que agora se diferencia por uma identidade organizacional caracterizada pela isenção, utilidade, confiabilidade das informações e proximidade com o ouvinte.

Conforme identificado na análise de conteúdo, organizações criativas como a emissora de rádio $\mathrm{X}$ têm como objetivo a busca por informações corretas, isentas, com espaço para a pluralidade. Além disso, cabe ao âncora a análise crítica, interpretando o que está por trás dos fatos (TAVARES \& GIOVANI, 2006). As entrevistas ressaltaram os aspectos de uma emissora de rádio que busca notícias que possam ser úteis ao ouvinte. Assim, as notícias devem servir como oportunidade de reflexão e formação de conteúdo para o público-alvo desta emissora.

Outra característica relevante nesta emissora é o âncora, através de sua atuação descontraída e dinâmica ao transmitir notícias e interagir com outros profissionais durante a transmissão. O âncora desta emissora de rádio parece transmitir a imagem de interesse e novidade, utilizando-se também de um português coloquial que facilita o relaxamento e a compreensão de que emissora rádio "não é bicho-de-sete-cabeças". Cabe ao âncora portanto, gerenciar a percepção de sua imagem perante os ouvintes. Assim, exige-se do âncora a competência do gerenciamento da impressão para auferir benefícios tais como agradar a audiência e manter a consistência entre as expectativas dos ouvintes e as imagens da organização (ROBERTS, 2005). Vale ressaltar que as questões importantes deste ramo são a proliferação do radiojornalismo e a chegada da rádio digital, que vai trazer ainda mais credibilidade a este setor, sem prescindir da importância do âncora para estimular a mudança e consolidação da identidade organizacional da emissora de rádio $\mathrm{X}$.

\section{Considerações finais}

Este artigo contribuiu abordou o tema da identidade organizacional na Indústria Criativa, através do caso de uma emissora de rádio. A identidade da emissora de rádio foi, durante muito tempo enquanto representante desta indústria, associada exclusivamente aos interesses oligárquicos, à música, ao entretenimento e a uma bela voz. Não obstante, esse artigo procurou mostrar a construção da identidade da emissora de rádio X que contrariou esses paradigmas. 


\section{Construção da identidade organizacional na indústria criativa: o caso de uma emissora de rádio}

Respondendo à pergunta da pesquisa, o processo de construção da identidade organizacional da emissora de rádio $\mathrm{X}$ foi caracterizado pela utilização intensa do âncora e de sua competência relacionada ao gerenciamento da impressão, para cativar ouvintes através de imagens pautadas na credibilidade, confiabilidade e prestatividade da informação.

Assim, observou-se que a identidade organizacional da emissora de rádio $\mathrm{X}$ está intrinsecamente ligada à imagem do âncora, que é um jornalista, repórter, entrevistador e gerenciador de impressões. A ideia de que a emissora de rádio não depende da imagem de seus interlocutores e está baseada única e exclusivamente em uma bela voz não parece corresponder mais à realidade. O próprio âncora é a imagem que a emissora de rádio $\mathrm{X}$ utiliza a todo momento para construir a identidade de uma emissora isenta, com informações corretas e com análise crítica sobre o que há por trás dos fatos.

As limitações deste trabalho abrangem o campo de estudo, que poderia incluir outras emissoras de rádio baseadas em entretenimento e música, ampliando assim a amostra de organizações. Futuras pesquisas podem abordar também o impacto da tecnologia da rádio digital sobre a identidade organizacional neste ramo. De qualquer modo, o âncora aparentemente permanecerá como o recurso principal deste ramo, devido ao seu papel na construção da identidade organizacional e nas imagens transmitidas pelas emissoras de rádio.

\section{Referências bibliográficas}

ALVESSON, M. Organization: from substance to image? Organization Studies, 11(3): 373-94, 1990.

BARDIN, L. Análise de conteúdo. Lisboa: Edições 70, 1977.

BENDASSOLLI, P.; WOOD Jr., T.; KIRSCHBAUM, C. \& PINA e CUNHA, M. Indústrias criativas: definições, limites e possibilidades. Revista de Administração de Empresas, 49(1): 10-18, 2009.

COOPER, D.R. \& SCHINDLER, P.S. Métodos de pesquisa em Administração. Porto Alegre: Bookman, 2003.

COOK, P. The creativity advantage is your organisation the leader of the pack? Industrial and Commercial Training, 30(5): 179-84, 1998.

CSIKSZENTMIHALYI, M. Creativity: Flow and psychology of discovery and invention. New York: Harper Collins, 1996. 
DEAN, A. \& KRETSCHMER, M. Can ideas be capital? Factors of production in the postindustrial economy: a review and critique. Academy of Management Review, 32(2): 573-94, 2007.

ELSBACH, K.D. \& BHATTACHARYA, C.B. Defining who you are by what you are not: organizational disidentification and the national rifle association. Organization Studies, 12(4): 393-413, 2001.

GIOIA, D.; SCHULTZ, M. \& CORLEY, K.G. Organization identity, image, and adaptative instability. Academy of Management Review, 25(1): 63-81, 2000.

HUBER, G.P. The nature and design of post-industrial organizations. Management Science, 30(8): 928-51, 1984.

JAMIESON, F. The workers independent news-the new face of labor media. The Journal of Labor and Society, 8: 483-88, 2005.

JONES, P.; COMFORT, D.; EASTWOOD, I. \& HILLIER, D. Creative industries: Economic contributions, management challenges and support initiatives. Management Research News. v. 27(11/12), 2004.

LANDRY, C. \& BIANCHINI, F. The creative city. London: Demos, 1995.

O'CONNOR, J. \& WYNNE, D. From the margins to the centre: Cultural production and consumption in the post-industrial city. Aldershot: Arena, 1996.

ROBERTS, L.M. Changing faces: professional image construction in diverse organization settings. Academy of Management Review, 30(4): 685-711, 2005.

ROBINSON, L. Radio research in transition. International Journal of Market Research, 42(4): 381-94, 2000.

ROBINSON, K. Out of our minds: Learning to be creative. London: Capstone, 2001.

TAVARES, M.; GIOVANI, F. (Orgs.). CBN, a rádio que toca notícia. RJ: Editora Senac Rio, 2006.

TEPPER, S. J. Creative assets and the changing economy. Journal of Arts Management, Law and Society, 5(2), 2002. 